\title{
Docetaxel promotes cell apoptosis and decreases SOX2 expression in CD133-expressing hepatocellular carcinoma stem cells by suppressing the PI3K/AKT signaling pathway
}

\author{
XUESONG ZHANG $^{1}$, JIANFENG SHAO ${ }^{1},{\text { XINYAN } \text { LI }^{2}, \text { LIHUA CUI }^{3} \text { and ZHENGBING TAN }}^{1}$ \\ ${ }^{1}$ Department of Infectious Diseases, Jingjiang People's Hospital, Jingjiang, Jiangsu 214500; \\ ${ }^{2}$ The First Department of Hepatitis, Zhongshan Hospital Affiliated to Fudan University, Xuhui, Guangdong 200032; \\ ${ }^{3}$ Department of Oncology, Jingjiang People's Hospital, Jingjiang, Jiangsu 214500, P.R. China
}

Received April 19, 2018; Accepted November 21, 2018

DOI: 10.3892/or.2018.6891

\begin{abstract}
Docetaxel is a front-line standard-of-care chemotherapeutic drug for the treatment of cancers. However, the underlying function and mechanism of docetaxel in human hepatocellular carcinoma (HCC) are uncertain. Therefore, the present study aimed to determine the effects of docetaxel on cell apoptosis and SOX2 expression in cultured human HCC stem cells. After human HCC stem cells were treated with docetaxel, cell proliferation was assessed by methyl thiazolyl tetrazolium (MTT) method, the cell apoptotic rate was evaluated by flow cytometry, the expression of CD133 and sex determining region Y-box 2 (SOX2) was determined by RT-PCR and immunohistochemistry, and the protein levels of CD133, SOX2, phosphoinositide 3-kinases (PI3K), AKT and phosphorylated AKT (p-AKT) were analyzed by western blotting. The results indicated that SOX2 and CD133 were highly expressed in patients with HCC while their expression was significantly decreased after patients with $\mathrm{HCC}$ were treated with docetaxel. In vitro, docetaxel inhibited the proliferation while it enhanced the apoptosis of human CD133-expressing HCC stem cells. Furthermore, lower expression of p-AKT and SOX2 were revealed in the presence of docetaxel. Notably, docetaxel-inhibited SOX2 expression and growth of human CD133-expressing HCC stem cells were partially restricted following the block of the PI3K/AKT signaling pathway using the inhibitor LY294002. The present study collectively indicated that docetaxel promoted apoptosis and upregulated
\end{abstract}

Correspondence to: Dr Zhengbing Tan, Department of Infectious Diseases, Jingjiang People's Hospital, 28 Zhongzhou Road, Jingjiang, Jiangsu 214500, P.R. China

E-mail: zb_t18@sina.com

Abbreviations: HCC, hepatocellular carcinoma; RT-PCR, reverse transcription-polymerase chain reaction; $\mathrm{SD}$, standard deviation

Key words: docetaxel, human liver cancer stem cell, PI3K/AKT, apoptosis, SOX
SOX2 expression of human HCC stem cells through the suppression of the PI3K/AKT signaling pathway.

\section{Introduction}

Despite the advances in therapeutic strategies in hepatocellular carcinoma (HCC) treatment, HCC is still one of the most common cancers worldwide (1). Recent studies have demonstrated that HCC stem cells that exist within the tumor mass have the ability to propagate and are considered to play an important role in liver tumor initiation, progression and metastasis (2). In addition, growing evidence has revealed that HCC stem cells are responsible for the resistance of chemotherapy and radiotherapy, and the recurrence of HCC (3). Thus, HCC stem cells are becoming crucial for evaluating new therapeutic strategies and monitoring the progress of HCC therapy.

CD133, also known as prominin-1, was first identified as a potential subpopulation of cancer stem cells $(4,5)$. It is now widely described as a marker of cancer stem cells in the brain (6), esophagus (7), lung (8), colon (9), prostate (10) and ovaries (11). Notably, CD133 is also a marker highly recognized in HCC stem cells (12), which is reported to be an important target for improving chemotherapeutic efficacy of recurrent HCC cells (13). CD133-expressing HCC stem cells have also been demonstrated to be involved in liver tumorigenicity in HCC, conferring radiotherapy resistance due to their high activation of the AKT/Protein kinase B (PKB), B-cell lymphoma 2 (Bcl-2) (14) and mitogen-activated protein kinase (MAPK)/PI3K (15) signaling pathways. In the present study, CD133-expressing HCC stem cells were chosen as an in vitro model.

Docetaxel belonging to the taxane family is a promising anticancer agent which is a semi-synthetic derivative from the needles of European yew (Taxus baccata) (16). Docetaxel has been widely used to treat breast (17), prostate (18), bladder (19), gastric (20), ovarian (21), head and neck (22) and non-small cell lung (23) cancers. Furthermore, the role of docetaxel in HCC treatment has been recognized due to its low toxicity and high therapeutic efficacy. Presently, docetaxel has demonstrated its ability to reduce the hepatocellular tumor size in nude mice and to inhibit the proliferation of the HepG2 cell 
line (24). After intravenously treating mice with $20 \mathrm{mg} / \mathrm{kg}$ silica nanorattle-encapsulated docetaxel, the hepatocellular tumor size of the mice was significantly decreased (25). However, the mechanism by which docetaxel maintains its antitumor capabilities in human CD133-expressing HCC stem cells remains to be explored.

The aim of the present study was to elucidate the mechanism by which docetaxel regulated SOX 2 expression and cell apoptosis in CD133-expressing HCC stem cells. We revealed that docetaxel inhibited SOX2 accumulation and induced cancer cell death through the suppression of the PI3K/AKT signaling pathway. Collectively, these findings revealed a novel mechanism that mediates the regulation of SOX 2 and the anticancer effects of docetaxel in human HCC stem cells.

\section{Materials and methods}

Patients and tissue samples. Normal liver tissues and HCC tissues used in this study were obtained between June 2016 and July 2017 from 48 HCC patients (aged 47.36 \pm 4.57 ; 36 male and 12 female patients) who had been treated with $20 \mathrm{mg} / \mathrm{kg}$ docetaxel (Sigma-Aldrich; Merck KGaA, Darmstadt, Germany) intravenously for a week at our hospital (Department of Oncology, Jingjiang People's Hospital, Jingjiang China). Informed consent was obtained from all patients. All experimental protocols were approved by the Institutional Ethics Committee of Jingjiang People's Hospital, Jiangsu, China (no. 2018-122).

Cell isolation and culture. Human normal liver stem cells and HCC stem cells were isolated from liver tissues of HCC patients at our hospital according to a previous study (26). Briefly, cell suspensions were centrifuged at $300 \mathrm{x}$ g for $10 \mathrm{~min}$ and cell pellets were resuspended in $300 \mu \mathrm{l}$ of buffer $/ 10^{8}$ total cells after aspirating the supernatant completely. Then, $100 \mu \mathrm{l}$ of FcR Blocking Reagent $/ 10^{8}$ total cells and $100 \mu \mathrm{l}$ of CD133/CD44/CD24 MicroBeads $/ 10^{8}$ total cells were added, mixed well and incubated for $30 \mathrm{~min}$ in the refrigerator. Cells were washed by adding 1-2 $\mathrm{ml}$ of buffer $/ 10^{8}$ cells and centrifuged at $300 \times \mathrm{g}$ for $10 \mathrm{~min}$. An appropriate MACS Column and MACS Separator was chosen according to the number of total cells and the number of $\mathrm{CD} 133^{+/} \mathrm{CD} 44^{+} / \mathrm{CD} 24^{+}$cells. The column was placed in the magnetic field of a suitable MACS Separator, and prepared by rinsing with $500 \mu \mathrm{l}$ buffer MS. The cell suspension was applied onto the column and washed with the appropriate amount of buffer. Unlabeled cells that passed through and combined with the effluent from the MS step were collected.Cells were maintained in Dulbecco's modified Eagle's medium (DMEM; Gibco-BRL Life Technologies; Thermo Fisher Scientific, Inc., Waltham, MA, USA) supplemented with $10 \%$ fetal bovine serum (FBS), $100 \mathrm{IU} / \mathrm{ml}$ penicillin, and $10 \mathrm{mg} / \mathrm{ml}$ streptomycin (Sigma-Aldrich; Merck KGaA) in an incubator with a humidified atmosphere of $5 \% \mathrm{CO}_{2}$ at $37^{\circ} \mathrm{C}$.

Cell viability assay. Cell viability was assessed using an MTT assay (Bestbio Biotechnology, Shanghai, China). Briefly, human HCC stem cells at a concentration of $2 \times 10^{3}$ cells/well were seeded in 96-well flat-bottomed tissue culture plates (Corning Inc., Corning, NY, USA) for 24 h. Following two washes with phosphate-buffered saline (PBS), cells were incubated in $100 \mu \mathrm{l}$ culture medium containing $50 \mathrm{nM}$ docetaxel for 12,24 and $48 \mathrm{~h}$ at $37^{\circ} \mathrm{C}$ prior to the MTT assay. Then, a total of $10 \mu \mathrm{MTT}$ and $100 \mu \mathrm{l}$ culture medium was added to each well, and following incubation for $1 \mathrm{~h}$ at $37^{\circ} \mathrm{C}$, the optical densities of the samples were measured directly using a spectrophotometric microplate reader (Beyotime Institute of Biotechnology, Haimen, China) at a wavelength of $490 \mathrm{~nm}$.

Cell apoptosis assay. The apoptotic cells were identified by the terminal-deoxynucleotidyl transferase mediated nick end-labeling (TUNEL) apoptosis assay kit (KeyGen Biotech Co., Ltd., Nanjing, China) according to manufacturer's instructions. Cells at a density of $2 \times 10^{4} / \mathrm{ml}$ were cultured in $10 \%$ FBS-containing DMEM with $50 \mathrm{nM}$ docetaxel for $24 \mathrm{~h}$ and harvested and washed twice with cold PBS by gentle shaking. Resuspended cells were added to $1 \mathrm{X}$ binding buffer and the cell density was adjusted to 200,000-500,000/ml. Cell apoptosis was analyzed using a FACScan flow cytometric apparatus (BD Biosciences, San Jose, CA, USA) and the percentage of apoptotic cells was analyzed using FlowJo 7.6.1 software (TreeStar, Inc., Ashland, OR, USA).

$R T-P C R$. The expression of CD133 and SOX2 in human HCC stem cells was assessed by RNA preparation and quantitative reverse transcription-polymerase chain reaction (RT-PCR). Total cellular RNA isolation using TRIzol reagent and cDNA synthesis using Takara PrimeScript II First Strand cDNA Synthesis kit (Invitrogen; Thermo Fisher Scientific, Inc.) was conducted according to the manufacturers' instructions. Specific primer sequences were synthesized in BioSune Biological Technology Corp. (Shanghai, China), and the sequences of the primers were as follows: CD133 forward, 5'-CCATACCTAGGTCCCCGTCC-3' and reverse, 5'-TTC ACTCAAGGCACCATCCC-3'; SOX2 forward, 5'-AACCAG CGCATGGACAGTTA-3' and reverse, 5'-GACTTGACCACC GAACCCAT-3'; GAPDH forward, 5'-AATGGGCAGCCG TTAGGAAA-3' and reverse, 5'-GCGCCCAATACGACCAAA TC-3'. Data was analyzed using Bio-Rad CFX Manager 1.6 Software (Bio-Rad Laboratories, Inc., Hercules, CA, USA.

Western blot analysis. Following the treatment with $50 \mathrm{nM}$ docetaxel for $6 \mathrm{~h}$, the cells were incubated for an additional $24 \mathrm{~h}$ prior to the collection of cells for protein extraction. The examination of the expression levels of CD133, SOX2, PI3K, AKT and p-AKT was then performed separately. Total protein was extracted using Total Protein Extraction kit (Sigma-Aldrich; Merck KGaA). Total protein was quantified using a bicinchoninic acid assay kit (Beyotime Institute of Biotechnology) and $30 \mu \mathrm{g}$ protein/lane was separated via SDS-PAGE on a $6 \%$ gel and run on a $10 \%$ gel. The separated proteins were subsequently transferred to nitrocellulose (NC) filter membrane and blocked with Tris-buffered saline (TBS) containing 5\% milk powder without fat and $0.05 \%$ Tween-20. Antibodies of CD133 (dilution 1:1,000; cat. no. sc-33182), PI3K (dilution 1:1,000; cat. no. 4922), AKT (dilution 1:1,000; cat. no. sc-9272) and p-AKT (dilution 1:1,000; cat. no. sc-33437) were purchased from Santa Cruz Biotechnology, Inc. (Santa Cruz, CA, USA). Antibodies of SOX2 (dilution 1:3,000; cat. no. 3579) and GAPDH (dilution 1:6,000; cat. no. 5174) were purchased from Cell Signaling Technology, Inc. (Beverly, MA, USA) 

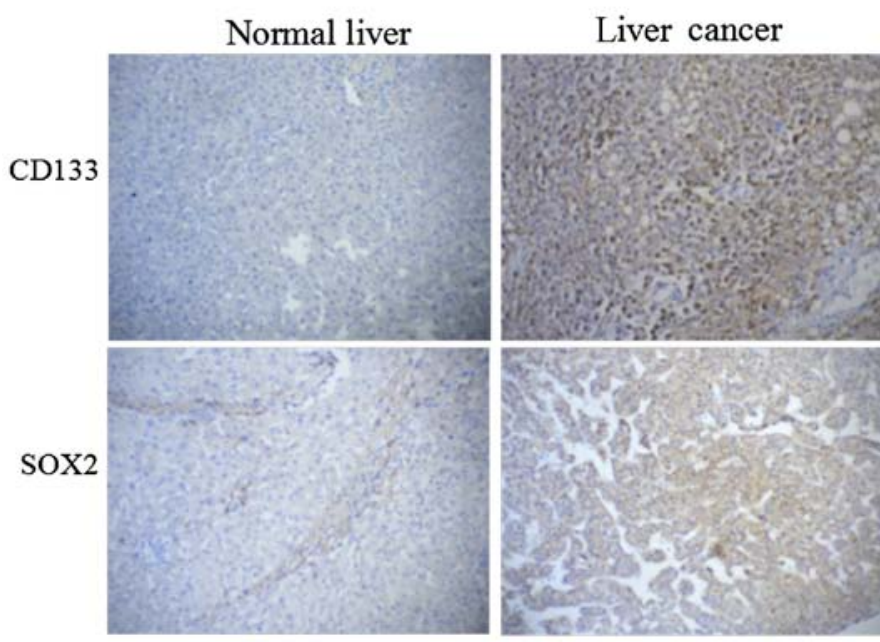

Docetaxel-treated
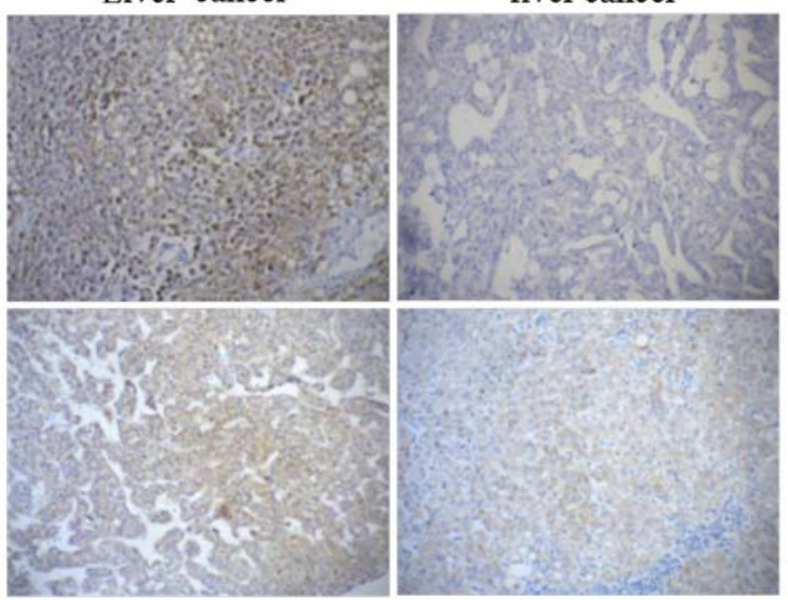

Figure 1. Docetaxel downregulates CD133 and SOX2 expression in human HCC patients. Expression of CD133 and SOX2 was assessed by immunohistochemistry in human HCC tissues and normal human liver tissues following docetaxel treatment. Each experiment was performed in triplicate and repeated six times.

A
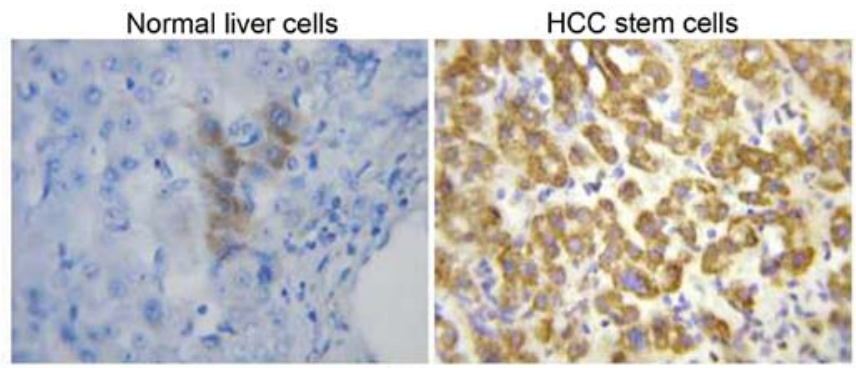

B
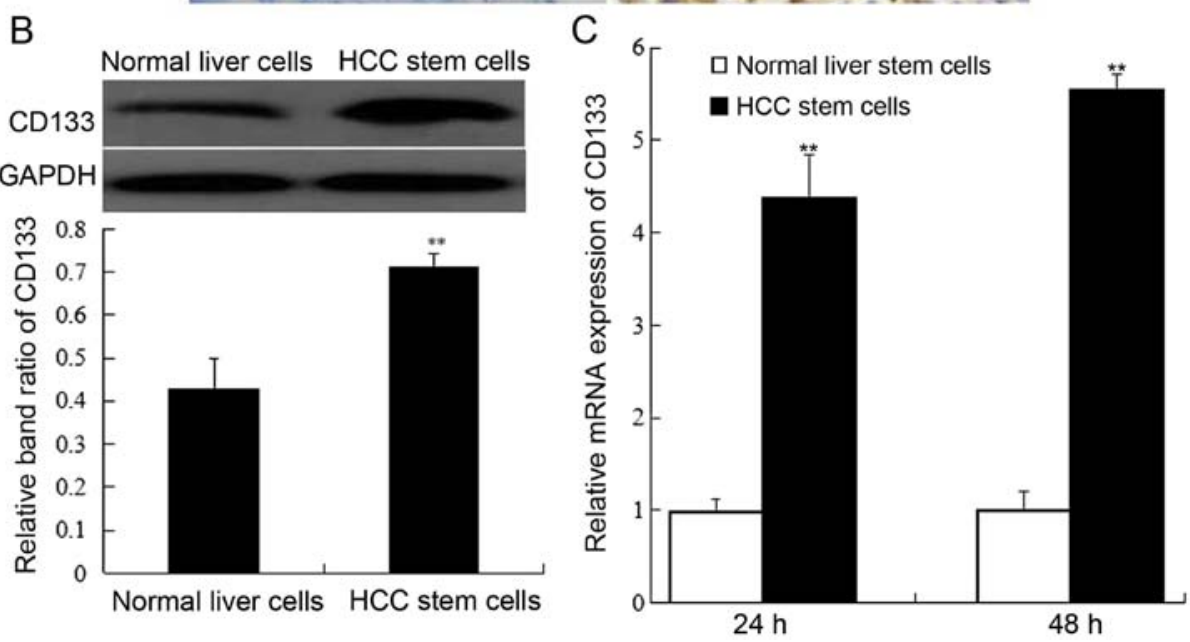

Figure 2. CD133 expression is determined in HCC stem cells. CD133 expression in normal liver stem cells and HCC stem cells was determined by (A) immunohistochemistry, (B) western blotting and (C) RT-PCR. Each experiment was performed in triplicate and repeated three times. Results were presented as the mean $\pm \mathrm{SD} .{ }^{* *} \mathrm{P}<0.01$ compared with the control.

and incubated at overnight at $4^{\circ} \mathrm{C}$. Secondary antibodies were conserved in our laboratory and incubated at $37^{\circ} \mathrm{C}$ for $1 \mathrm{~h}$. The protein levels were detected using the chemiluminescence reader, ImageQuant ${ }^{\mathrm{TM}}$ LAS4000 (GE Healthcare Bio-Sciences, Pittsburgh, PA, USA). Relative band ratio was analyzed using ImageJ software (version 1.48; National Institutes of Health, Bethesda, MD, USA).

Immunohistochemistry. Paraffin-embedded normal liver and cancer liver tissues (3- $\mu \mathrm{m}$ in thickness) were prepared and immunohistochemistry was performed as previously described (27). Primary antibodies against CD133 (dilution 1:500; Santa Cruz Biotechnology, Inc.) and SOX2 (dilution 1:200; Abcam, Cambridge, UK) were used. Data of immunohistochemistry were analyzed using Image-Pro Plus (version 4.1; Media Cybernetics, Rockville, MD, USA).

Block of PI3K/AKT signal using an inhibitor. Human HCC stem cells were treated with PI3K/AKT inhibitor LY294002 at a concentration of $25 \mu \mathrm{M}$ for $48 \mathrm{~h}$, followed by the addition of $50 \mathrm{nM}$ docetaxel and further incubation for $48 \mathrm{~h}$. Then, cell proliferation, apoptosis, and SOX2 expression were evaluated. 

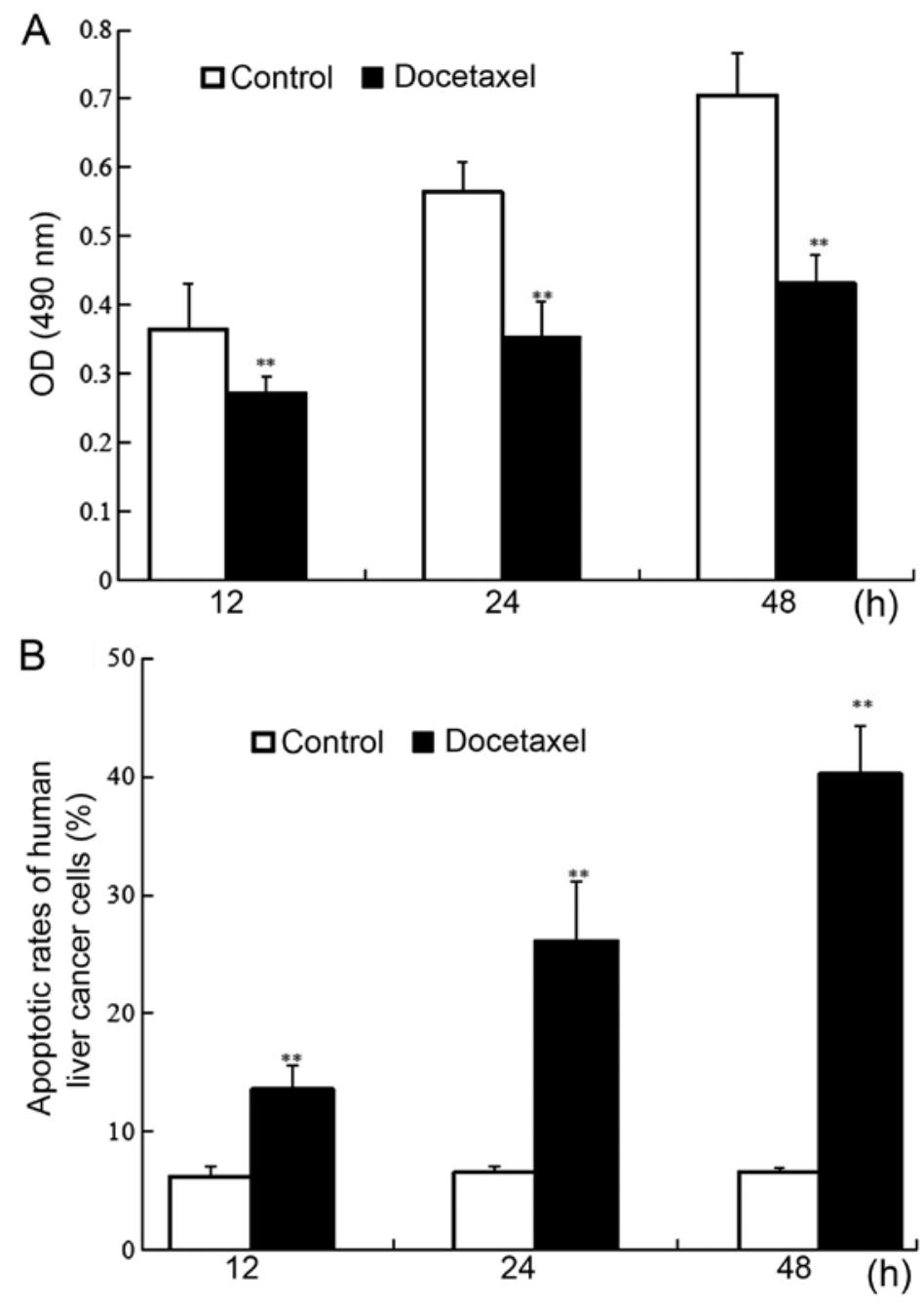

Figure 3. Docetaxel inhibits the growth of human CD133-expressing HCC stem cells. Human HCC stem cells were treated with docetaxel for 12, 24 and $48 \mathrm{~h}$ and cell proliferation was assessed by (A) MTT assay, and (B) cell apoptosis was determined by flow cytometry. Each experiment was performed in triplicate and repeated six times. Results were presented as the mean $\pm \mathrm{SD} .{ }^{* *} \mathrm{P}<0.01$ compared with the control.

Statistical analysis. All results were analyzed by one-way analysis of variance (ANOVA) using the SPSS 17.0 statistical software (SPSS, Inc., Chicago, IL, USA). Data are presented as the mean \pm standard deviation (SD). Boferroni's post hoc test was used to determine the statistical differences between the treatment and control groups. P-values were based on the two-sided statistical analysis, and $\mathrm{P}<0.05$ was considered to indicate a statistically significant difference.

\section{Results}

Docetaxel downregulates the expression of CD133 and SOX2 in patients with HCC. As shown in Fig. 1, higher expression of CD133 and SOX2 was detected by immunohistochemistry in HCC samples compared with normal liver tissues, indicating that CD133 and SOX2 were two important factors which may be involved in HCC. Moreover, the expression of CD133 and SOX2 in human HCC tissues was significantly downregulated by docetaxel compared to cells without docetaxel stimulation.

Identification of CD133-expressing HCC stem cells. Following 24 and $48 \mathrm{~h}$ of cell culture, CD133 expression in normal liver stem cells and HCC stem cells was determined by immunohistochemistry, western blotting and RT-PCR. The results revealed that the percentage of CD133-positive cells was obviously higher in HCC stem cells than that of normal liver stem cells (Fig. 2A). Additionally, compared to normal liver stem cells, CD133 protein expression was highly promoted in HCC stem cells ( $\mathrm{P}<0.01)$. (Fig. 2B). The assessment of CD133 mRNA expression also supported the conclusion that CD133 expression was increased in HCC stem cells (Fig. 2C).

Docetaxel inhibits the proliferation while promoting the apoptotic rate of human CD133-expressing HCC stem cells. Human CD133-expressing HCC stem cells were respectively exposed to docetaxel for 12, 24 and $48 \mathrm{~h}$, and the role of docetaxel in human CD133-expressing HCC stem cells was assessed through MTT assay and flow cytometry. The results revealed that compared to the control without docetaxel treatment, docetaxel significantly downregulated cell viability in CD133-expressing HCC stem cells in a time-dependent manner $(\mathrm{P}<0.01)$ (Fig. 3A). Conversely, as shown in Fig. 3B, docetaxel significantly promoted apoptosis in CD133-expressing HCC stem cells in a time-dependent manner. Approximately 13.58, 26.13 and $40.24 \%$ of cells underwent apoptosis after exposure to docetaxel for 12, 24 and $48 \mathrm{~h}$, respectively, and there was a 

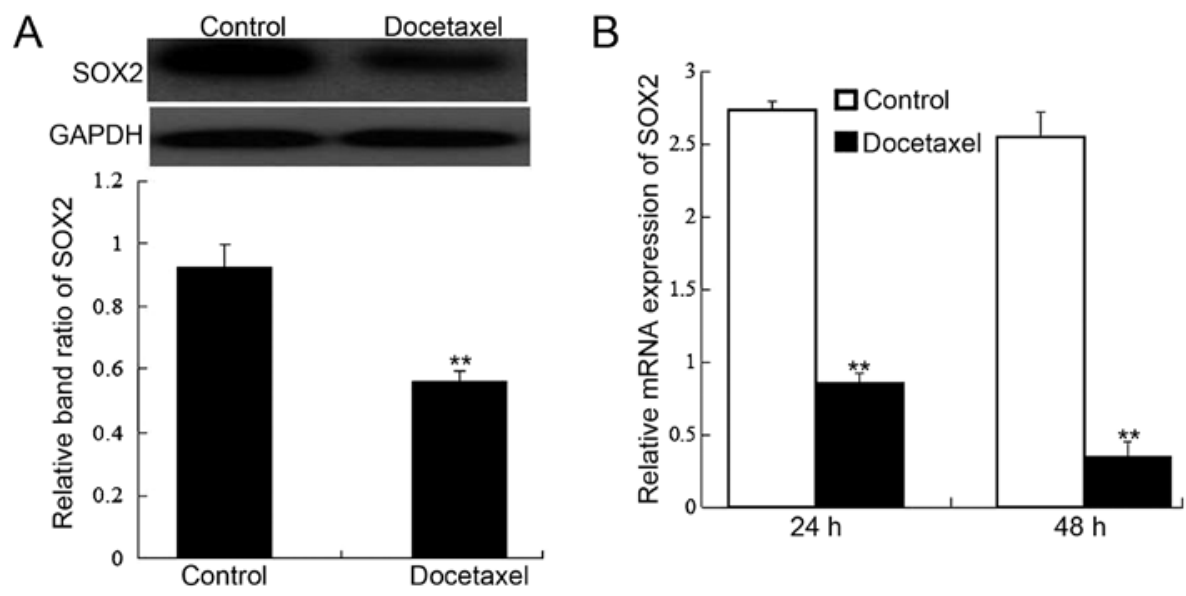

Figure 4. Docetaxel decreases SOX2 expression in human CD133-expressing HCC stem cells. After human HCC stem cells were stimulated with docetaxel, SOX2 protein expression was detected by (A) western blotting and (B) SOX2 mRNA expression was evaluated using RT-PCR. Results were presented as the mean \pm SD. ${ }^{* *} \mathrm{P}<0.01$ compared with the control.

A
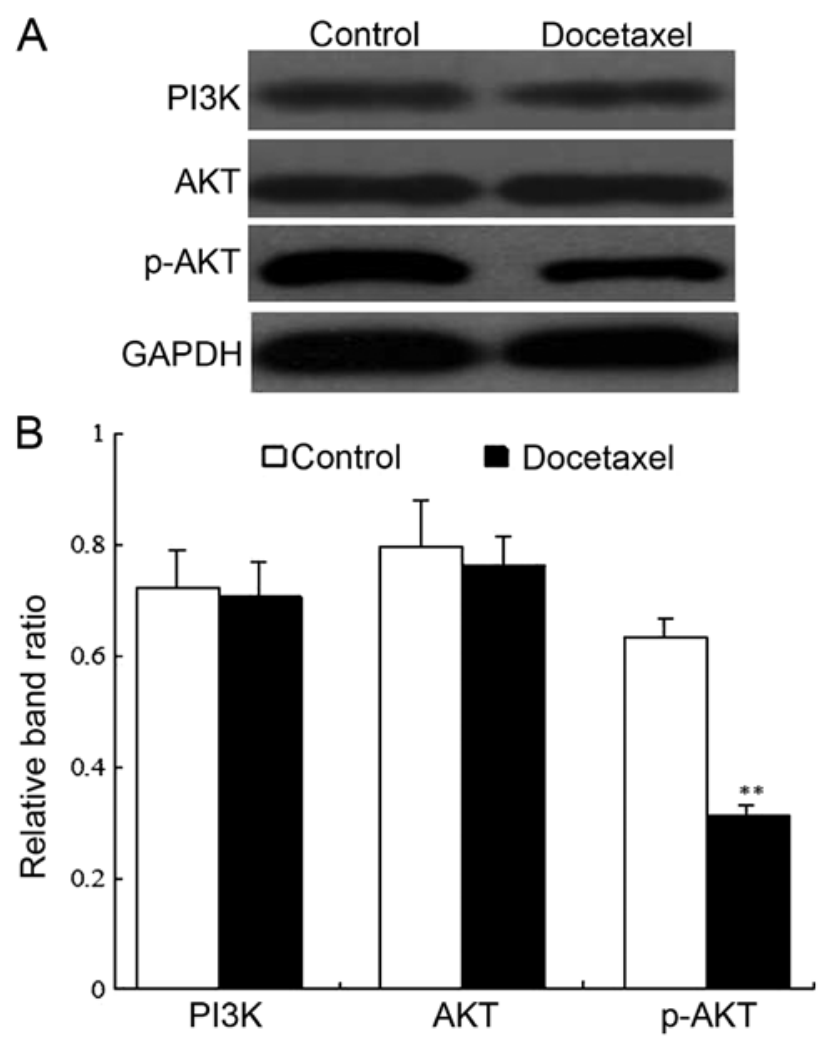

Figure 5. Docetaxel suppresses the PI3K/AKT signaling pathway in human HCC stem cells. (A) After human HCC cells were treated with docetaxel for 48 h, the protein expression of PI3K, AKT and p-AKT was assessed by western blotting. (B) Relative band ratio was analyzed using ImageJ software. Each experiment was performed in triplicate and repeated three times. Results were presented as the means $\pm \mathrm{SD}$. ${ }^{* *} \mathrm{P}<0.01$ compared with the control.

significant difference between docetaxel-treated groups and the control without docetaxel treatment $(\mathrm{P}<0.01)$. The findings above indicated that docetaxel significantly increased the apoptosis in CD133-expressing HCC stem cells.

Docetaxel suppresses the expression of SOX2 in human CD133-expressing HCC stem cells. Since SOX2 expression is associated with HCC, we further detected SOX2 protein and mRNA expression using western blotting and RT-PCR at indicated time-points after docetaxel stimulation. The results demonstrated that SOX2 protein (Fig. 4A) and mRNA (Fig. 4B) expression was significantly inhibited by docetaxel in human HCC stem cells $(\mathrm{P}<0.05)$ in comparison with the control.

Docetaxel inhibits the PI3K/AKT signaling pathway in human CD133-expressing HCC stem cells. To further verify the underlying mechanisms of docetaxel in human CD133-expressing HCC stem cells, we explored the expression of PI3K, AKT and p-AKT by western blotting (Fig. 5A). Band analysis indicated that the protein level of PI $3 \mathrm{~K}$ and AKT exhibited no difference 
A

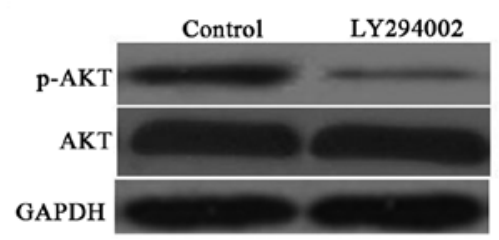

C

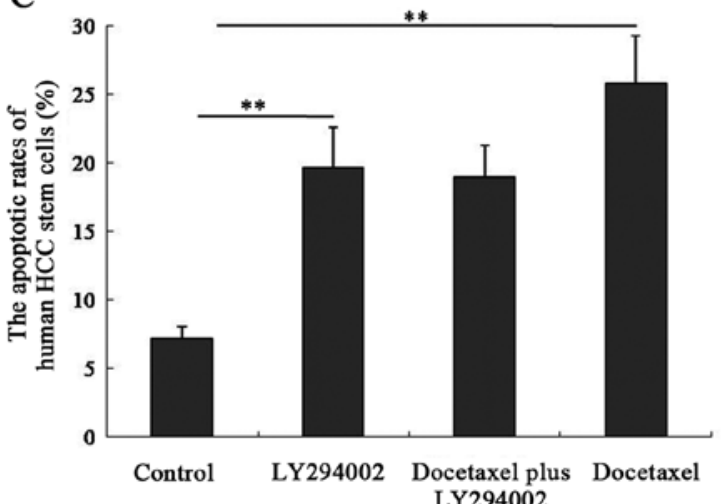

B
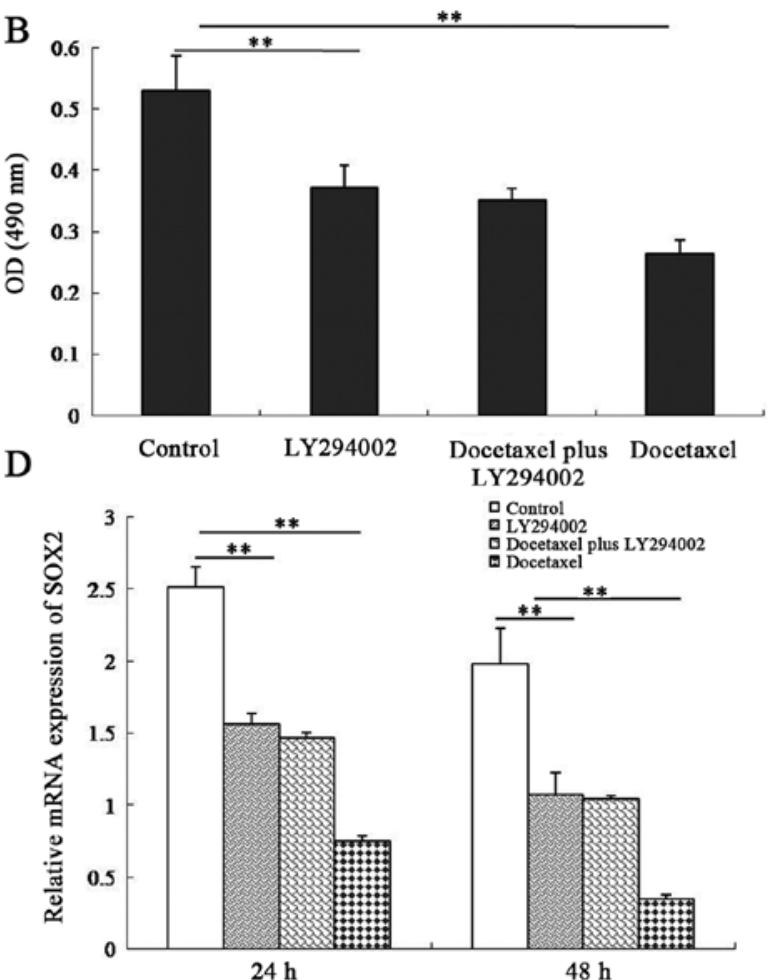

Figure 6. Docetaxel induces cell apoptosis and decreases SXO2 expression in human CD133-expressing HCC stem cells through the PI3K/AKT signaling pathway. After the PI3K/AKT signaling pathway was blocked using LY294002, protein expression of p-AKT was assessed by (A) western blotting. Human HCC cells were stimulated with docetaxel, LY294002 or docetaxel plus LY294002 and (B) cell proliferation, (C) the apoptotic rate and (D) the mRNA expression of SOX2 were determined. Each experiment was performed in triplicate and repeated three times. Results were presented as the means \pm SD. ${ }^{* *} \mathrm{P}<0.01$ compared with the control.

between the docetaxel-treated group and non-docetaxel-treated group $(\mathrm{P}>0.05)$. Moreover, the $\mathrm{p}-\mathrm{AKT}$ protein level was comparatively low in docetaxel-treated cells in comparison with the control $(\mathrm{P}<0.01)($ Fig. $5 \mathrm{~B})$. It was thus suggested that docetaxel could suppress the PI3K/AKT signaling pathway in human CD133-expressing HCC stem cells.

Inhibition of the PI3K/AKT signaling pathway in human CD133-expressing HCC stem cells is required for docetaxel-induced cell apoptosis and decreased SOX2 expression. We next examined the influence of the PI3K/AKT signaling on docetaxel-induced cell apoptosis and -decreased SOX2 expression in human CD133-expressing HCC stem cells. The results revealed that HCC stem cells treated with the PI3K/AKT inhibitor LY294002 exhibited a significant decrease in p-AKT expression compared with untreated cells (Fig. 6A). Cell viability (Fig. 6B) and SOX2 expression (Fig. 6D) were inhibited in both LY294002-treated cells and docetaxel-treated cells. However, there was no difference in cell viability and SOX2 expression between LY294002 plus docetaxel-treated cells and LY294002-treated cells ( $\mathrm{P}>0.05)$. As demonstrated in Fig. 6C, LY294002 or docetaxel significantly promoted the apoptotic rate in CD133-expressing HCC stem cells $(\mathrm{P}<0.01)$. Moreover, the apoptotic rate exhibited no difference between the LY294002-treated group and LY294002 plus docetaxel-treated group ( $P>0.05)$. These results indicated that the PI3K/AKT signaling pathway was involved in docetaxel-exerted biological functions in human CD133-expressing HCC stem cells.

\section{Discussion}

In the present study, we investigated the mechanisms underlying docetaxel-induced cell apoptosis in CD133-expressing HCC stem cells. We determined that docetaxel induced the suppression of the PI3K/AKT signaling pathway, thereby causing HCC stem cell death and decreased SOX2 expression.

Docetaxel has been used to treat various types of cancers. In vitro, docetaxel suppresses proliferation and induces apoptosis by suppressing the mitogen-activated protein kinase (MAPK) signaling in renal cell carcinoma cells (28). Docetaxel induces cell apoptosis and suppresses cell proliferation in non-small cell lung cancer cells by upregulating microRNA-7 expression (29). In a study on HCC treatment with docetaxel, Geng et al demonstrated that docetaxel enhanced radiation sensitivity of human HCC cells (30). Additionally, another study from the same authors provided the evidence that docetaxel reduced the proliferation of SMMC-7721 HCC cells in vitro, kept their morphology, and induced cell death by apoptosis (31). Docetaxel was revealed to inhibit the growth of hepatoma cells by arresting the G2/M-phase, activating caspases, and fragmenting DNA (32). A recent investigation confirmed that docetaxel inhibited the progression of cultured human hepatoma cells in advanced HCC (33). In the present study, we also revealed that docetaxel inhibited proliferation while promoting apoptosis in CD133-expressing HCC stem cells through the inactivation of the PI3K/AKT signaling pathway. 
According to research, SOX2, a major transcription factor is regarded as a stemness-related factor. It has been demonstrated that SOX2 is associated with various types of cancers and has been used as a marker to identify cancer stem cells (34). Furthermore, SOX2 suppression is mandatory for cellular differentiation. For these reasons, SOX2 has been investigated in cancer stem cells in several cancer types. Notably, predictive value of SOX2 in cancers is associated with the prognosis of patients and is regarded as a possible therapeutic target. In a review study, the role of SOX2 as a prognostic marker, indicator of metastasis, or biomarker in cancer pathogenesis was highlighted (35). Recently, numerous studies have provided evidence that SOX 2 mRNA expression was significantly higher in patients with small-cell lung (36), gastric (37), breast (38), cervical (39) and ovarian epithelial cancer (40) compared to the healthy controls. A high level of SOX2 expression was revealed to be correlated with metastasis and a low survival rate in HCC (41). In the present study, we attempted to reveal the relationship between docetaxel and SOX2, and demonstrated that protein and mRNA expression of SOX2 exhibited a significant decrease in docetaxel-treated HCC stem cells.

In order to investigate the mechanisms underlying the antitumor effects of docetaxel in CD133-expressing HCC stem cells, the activation of the PI3K/AKT signaling pathway was determined after cells were treated with docetaxel. Our results demonstrated that $\mathrm{p}-\mathrm{AKT}$ expression was significantly decreased in the drug-treated CD133-expressing HCC stem cells compared with that of the control group, indicating that the suppression of the PI3K/AKT signaling pathway occured in the presence of docetaxel, and this signal suppression was involved in the changes induced by docetaxel in CD133-expressing HCC stem cells. Previous studies have indicated that PI3K is a type of lipid kinase, and its cascades play an essential role in regulating growth, migration, and survival of different types of tumor cells (42). Additionally, accumulating evidence has revealed that PI3K/AKT was associated with tumorigenesis, cancer progression and drug resistance (43). Several drugs targeting PI3K/ATK are currently used in clinical trials to treat cancers (44-46). Previous research has revealed that docetaxel induced the apoptosis in human prostate cancer cells by modulating the PI3K/AKT pathway (47). Thus, docetaxel and its target PI3K/AKT may offer a new direction for cancer therapy.

In summary, we reported for the first time, to the best of our knowledge, that docetaxel inhibited the growth of human CD133-expressing HCC stem cells by causing cell apoptosis. Further investigation revealed that the PI3K/AKT signaling pathway played a key role in docetaxel-induced apoptosis of human CD133-expressing HCC stem cells. These findings may add new insights to HCC stem cells and help to explore their functions in tumor therapy.

\section{Acknowledgements}

Not applicable.

\section{Funding}

No funding was received.

\section{Availability of data and materials}

The datasets used during the present study are available from the corresponding author upon reasonable request.

\section{Authors' contributions}

$\mathrm{XZ}$ and $\mathrm{ZT}$ were involved in the manuscript preparation and the conception of the study; XZ, JS and ZT were responsible for the manuscript editing, reviewing and study design, carried out the experimental studies and were involved in the data acquisition; XZ, XL and ZT were responsible for revising the manuscript critically for important intellectual content; $\mathrm{XZ}, \mathrm{XL}, \mathrm{LC}$ and ZT performed the literature research; XL and LC were involved in the clinical studies; XZ, XL and LC were responsible for the data analysis; $\mathrm{XZ}$ and $\mathrm{LC}$ performed the statistical analysis. All authors read and approved the manuscript and agree to be accountable for all aspects of the research in ensuring that the accuracy or integrity of any part of the work are appropriately investigated and resolved.

\section{Ethics approval and consent to participate}

All experimental protocols were approved by the Institutional Ethics Committee of Jingjiang People's Hospital, Jiangsu, China (no. 2018-122). Informed consent was obtained from all patients.

\section{Patient consent for publication}

Not applicable.

\section{Competing interests}

The authors declare that they have no competing interests.

\section{References}

1. Forner A, Llovet JM and Bruix J: Hepatocellular carcinoma. Lancet 379: 1245-1255, 2012.

2. Sun JH, Luo Q, Liu LL and Song GB: Liver cancer stem cell markers: Progression and therapeutic implications. World $\mathrm{J}$ Gastroenterol 22: 3547-3557, 2016.

3. Karakasiliotis I and Mavromara P: Hepatocellular carcinoma: From hepatocyte to liver cancer stem cell. Front Physiol 6: 154, 2015.

4. Grosse-Gehling P, Fargeas CA, Dittfeld C, Garbe Y, Alison MR, Corbeil D and Kunz-Schughart LA: CD133 as a biomarker for putative cancer stem cells in solid tumours: Limitations, problems and challenges. J Pathol 229: 355-378, 2013.

5. Suetsugu A, Nagaki M, Aoki H, Motohashi T, Kunisada T and Moriwaki H: Characterization of CD133 $3_{+}$hepatocellular carcinoma cells as cancer stem/progenitor cells. Biochem Biophys Res Commun 351: 820-824, 2006.

6. Li B, McCrudden CM, Yuen HF, Xi X, Lyu P, Chan KW, Zhang SD and Kwok HF: CD133 in brain tumor: The prognostic factor. Oncotarget 8: 11144-11159, 2017.

7. Okamoto K, Ninomiya I, Ohbatake Y, Hirose A, Tsukada T, Nakanuma S, Sakai S, Kinoshita J, Makino I, Nakamura K, et al: Expression status of CD44 and CD133 as a prognostic marker in esophageal squamous cell carcinoma treated with neoadjuvant chemotherapy followed by radical esophagectomy. Oncol Rep 36: 3333-3342, 2016.

8. Tu Z, Xie S, Xiong M, Liu Y, Yang X, Tembo KM, Huang J, Hu W, Huang X, Pan S, et al: CXCR4 is involved in CD133-induced EMT in non-small cell lung cancer. Int J Oncol 50: 505-514, 2017. 
9. Shmelkov SV, Butler JM, Hooper AT, Hormigo A, Kushner J, Milde T, St Clair R, Baljevic M, White I, Jin DK, et al: CD133 expression is not restricted to stem cells, and both $\mathrm{CD} 133^{+}$and CD133- metastatic colon cancer cells initiate tumors. J Clin Invest 118: 2111-2120, 2008.

10. Vander Griend DJ, Karthaus WL, Dalrymple S, Meeker A, DeMarzo AM and Isaacs JT: The role of CD133 in normal human prostate stem cells and malignant cancer-initiating cells. Cancer Res 68: 9703-9711, 2008.

11. Qin Q, Sun Y, Fei M, Zhang J, Jia Y, Gu M, Xia R, Chen S and Deng A: Expression of putative stem marker nestin and CD133 in advanced serous ovarian cancer. Neoplasma 59: 310-315, 2012

12. Jang JW, Song Y, Kim SH, Kim JS, Kim KM, Choi EK, Kim J and Seo HR: CD133 confers cancer stem-like cell properties by stabilizing EGFR-AKT signaling in hepatocellular carcinoma. Cancer Lett 389: 1-10, 2017.

13. Xi G, Li YD, Grahovac G, Rajaram V, Wadhwani N, Pundy T, Mania-Farnell B, James CD and Tomita T: Targeting CD133 improves chemotherapeutic efficacy of recurrent pediatric pilocytic astrocytoma following prolonged chemotherapy. Mol Cancer 16: 21, 2017.

14. Ma S, Lee TK, Zheng BJ, Chan KW and Guan XY: CD133+ HCC cancer stem cells confer chemoresistance by preferential expression of the Akt/PKB survival pathway. Oncogene 27: 1749-1758, 2008.

15. Zhang L, Li H, Ge C, Li M, Zhao FY, Hou HL, Zhu MX, Tian H, Zhang LX, Chen TY, et al: Inhibitory effects of transcription factor Ikaros on the expression of liver cancer stem cell marker CD133 in hepatocellular carcinoma. Oncotarget 5: 10621-10635, 2014.

16. Guéritte-Voegelein F, Guénard D, Dubois J, Wahl A and Potier P: Chemical and biological studies on Taxol (Paclitaxel) and Taxotere (Docetaxel), new antineoplastic agents. J Pharm Belg 49: 193-205, 1994 (In French).

17. Seguin C, Kovacevich N and Voutsadakis IA: Docetaxelassociated myalgia-arthralgia syndrome in patients with breast cancer. Breast Cancer 9: 39-44, 2017.

18. Belz J, Castilla-Ojo N, Sridhar S and Kumar R: Radiosensitizing silica nanoparticles encapsulating docetaxel for treatment of prostate cancer. Methods Mol Biol 1530: 403-409, 2017.

19. Albany $\mathrm{C}$ and Sonpavde G: Docetaxel for the treatment of bladder cancer. Expert Opin Investig Drugs 24: 1657-1664, 2015.

20. Dassen AE, Bernards N, Lemmens VE, van de Wouw YA, Bosscha K, Creemers GJ and Pruijt HJ: Phase II study of docetaxel, cisplatin and capecitabine as preoperative chemotherapy in resectable gastric cancer. World J Gastrointest Surg 8: 706-712, 2016

21. Hami Z, Rezayat SM, Gilani K, Amini M and Ghazi-Khansari M: In-vitro cytotoxicity and combination effects of the docetaxelconjugated and doxorubicin-conjugated poly(lactic acid)-poly(ethylene glycol)-folate-based polymeric micelles in human ovarian cancer cells. J Pharm Pharmacol 69: 151-160, 2017.

22. Posch D, Fuchs H, Kornek G, Grah A, Pammer J, Aretin MB and Fuereder T: Docetaxel plus cetuximab biweekly is an active regimen for the first-line treatment of patients with recurrent/metastatic head and neck cancer. Sci Rep 6: 32946, 2016.

23. Fukae M, Shiraishi Y, Hirota T, Sasaki Y, Yamahashi M, Takayama K, Nakanishi Y and Ieiri I: Population pharmacokinetic-pharmacodynamic modeling and model-based prediction of docetaxel-induced neutropenia in Japanese patients with non-small cell lung cancer. Cancer Chemother Pharmacol 78: 1013-1023, 2016.

24. Zhu D, Tao W, Zhang H, Liu G, Wang T, Zhang L, Zeng X and Mei L: Docetaxel (DTX)-loaded polydopamine-modified TPGS-PLA nanoparticles as a targeted drug delivery system for the treatment of liver cancer. Acta Biomater 30: 144-154, 2016.

25. Li L, Tang F, Liu H, Liu T, Hao N, Chen D, Teng X and He J: In vivo delivery of silica nanorattle encapsulated docetaxel for liver cancer therapy with low toxicity and high efficacy. ACS Nano 4: 6874-6882, 2010.

26. Pu H, Zheng Q, Li H, Wu M, An J, Gui X, Li T and Lu D: CUDR promotes liver cancer stem cell growth through upregulating TERT and C-Myc. Oncotarget 6: 40775-40798, 2015.
27. Feng X, Zhu K, Liu J, Chen J, Tang J, Liang Y, Jin R, Liang X and Cai X: The evaluative value of Sema3C and MFN2 co-expression detected by immunohistochemistry for prognosis in hepatocellular carcinoma patients after hepatectomy. Onco Targets Ther 9: 3213-3221, 2016.

28. Han TD, Shang DH and Tian Y: Docetaxel enhances apoptosis and $\mathrm{G} 2 / \mathrm{M}$ cell cycle arrest by suppressing mitogen-activated protein kinase signaling in human renal clear cell carcinoma. Genet Mol Res 15, 2016.

29. He X, Li C, Wu X and Yang G: Docetaxel inhibits the proliferation of non-small-cell lung cancer cells via upregulation of microRNA-7 expression. Int J Clin Exp Pathol 8: 9072-9080, 2015.

30. Geng CX, Zeng ZC, Wang JY, Xuan SY and Lin CM: Docetaxel shows radiosensitization in human hepatocellular carcinoma cells. World J Gastroenterol 11: 2990-2993, 2005.

31. Geng CX,Zeng ZC and Wang JY: Docetaxel inhibits SMMC-7721 human hepatocellular carcinoma cells growth and induces apoptosis. World J Gastroenterol 9: 696-700, 2003.

32. Lin HL, Liu TY, Chau GY, Lui WY and Chi CW: Comparison of 2-methoxyestradiol-induced, docetaxel-induced, and paclitaxel-induced apoptosis in hepatoma cells and its correlation with reactive oxygen species. Cancer 89: 983-994, 2000.

33. Yata Y, Xue F, Takahara T, Kudo H, Hirano K, Yasumura S, Minemura M, Scanga AE and Sugiyama T: Docetaxel inhibits progression of human hepatoma cell line in vitro and is effective in advanced hepatocellular carcinoma. Hepatol Res 40: 304-310, 2010.

34. Yang L, Xu JF, Kang Q, Li AQ, Jin P, Wang X, He YQ, Li N, Cheng T and Sheng JQ: Predictive value of stemness factor Sox2 in gastric cancer is associated with tumor location and stage. PLoS One 12: e0169124, 2017.

35. Weina K and Utikal J: SOX 2 and cancer: Current research and its implications in the clinic. Clin Transl Med 3: 19, 2014.

36. Sodja E, Rijavec M, Koren A, Sadikov A, Korošec P and Cufer T: The prognostic value of whole blood SOX2, NANOG and OCT4 mRNA expression in advanced small-cell lung cancer. Radiol Oncol 50: 188-196, 2016.

37. Carrasco-Garcia E,Santos JC,Garcia I, Brianti M,García-Puga M, Pedrazzoli J Jr, Matheu A and Ribeiro ML: Paradoxical role of SOX2 in gastric cancer. Am J Cancer Res 6: 701-713, 2016.

38. Zheng Y, Qin B, Li F, Xu S, Wang S and Li L: Clinicopathological significance of Sox 2 expression in patients with breast cancer: A meta-analysis. Int J Clin Exp Med 8: 22382-22392, 2015.

39. Kim BW, Cho H, Choi CH, Ylaya K, Chung JY, Kim JH and Hewitt SM: Clinical significance of OCT4 and SOX2 protein expression in cervical cancer. BMC Cancer 15: 1015, 2015.

40. Du J, Li B, Fang Y, Liu Y, Wang Y, Li J, Zhou W and Wang X: Overexpression of Class III $\beta$-tubulin, Sox 2 , and nuclear Survivin is predictive of taxane resistance in patients with stage III ovarian epithelial cancer. BMC Cancer 15: 536, 2015.

41. Sun C, Sun L, Li Y, Kang X, Zhang S and Liu Y: Sox 2 expression predicts poor survival of hepatocellular carcinoma patients and it promotes liver cancer cell invasion by activating Slug. Med Oncol 30: 503, 2013.

42. Cantley LC: The phosphoinositide 3-kinase pathway. Science 296: 1655-1657, 2002.

43. Guerrero-Zotano A,MayerIA and ArteagaCL:PI3K/AKT/mTOR: Role in breast cancer progression, drug resistance, and treatment. Cancer Metastasis Rev 35: 515-524, 2016.

44. Sharma VR, Gupta GK, Sharma AK, Batra N, Sharma DK, Joshi A and Sharma AK: PI3K/Akt/mTOR Intracellular Pathway and Breast Cancer: Factors, Mechanism and Regulation. Curr Pharm Des 23: 1633-1638, 2017.

45. Gao Y, Xiao X, Zhang C, Yu W, Guo W, Zhang Z, Li Z, Feng X, Hao J, Zhang K, et al: Melatonin synergizes the chemotherapeutic effect of 5-fluorouracil in colon cancer by suppressing PI3K/AKT and NF- $\kappa$ B/iNOS signaling pathways. J Pineal Res 62, 2017.

46. Luo Y, Wu JY, Lu MH, Shi Z, Na N and Di JM: Carvacrol alleviates prostate cancer cell proliferation, migration, and invasion through regulation of PI3K/Akt and MAPK signaling pathways. Oxid Med Cell Longev 2016: 1469693, 2016.

47. Dirican A, Atmaca H, Bozkurt E, Erten C, Karaca B and Uslu R: Novel combination of docetaxel and thymoquinone induces synergistic cytotoxicity and apoptosis in DU-145 human prostate cancer cells by modulating PI3K-AKT pathway. Clin Transl Oncol 17: 145-151, 2015. 